\title{
Efficient Performance of Chiral Boron Nitride Nanotubes as Suitable Selector for Separation of Ibuprofen Enantiomers Using DFT-D3 Calculations and Molecular Dynamics Simulation
}

\section{Melahatsadat Rasoolidanesh}

Islamic Azad University Medical Branch of Tehran

Masoud Darvish Ganji ( $\sim$ ganji_md@yahoo.com)

Qaemshahr Islamic Azad University

Keywords:

Posted Date: January 29th, 2021

DOI: https://doi.org/10.21203/rs.3.rs-154454/v1

License: (c) (1) This work is licensed under a Creative Commons Attribution 4.0 International License.

Read Full License 


\section{Abstract}

The authors have requested that this preprint be removed from Research Square. 